\title{
镍催化的轴手性联芳基化合物不对称电化学合成
}

\author{
蒋洋叶曾程初* \\ (北京工业大学生命科学与生物工程学院 北京 100124)
}

\section{Enantioselective Ni-Catalyzed Electrochemical Synthesis of Biaryl Atropisomers}

\author{
Jiang, Yangye Zeng, Chengchu* \\ (College of Life Science \& Bioengineering, Beijing University of Technology, Beijing 100124)
}

轴手性联芳基化合物是有机配体、有机催化剂、天 然产物和药物分子的核心骨架，建立方便、高效、可规 模化制备该类化合物的方法十分重要.

联芳基化合物的合成可通过芳基卤化物与芳基金 属化合物的交叉偶联反应 ${ }^{[1]}$ (Scheme 1a)或 2-菜酚的不对 称氧化偶联反应 ${ }^{[2]}($ Scheme $1 b)$ 等途径来实现. 在第一种 方法中，由于原料芳基金属化合物需要预先由芳基卤化 物与金属反应来制备, 因此, 芳基卤代物的直接还原偶 联的方法更为简洁、高效. 目前, 以锰、锌或镁粉为还 原剂, 镍为催化剂的芳基卤化物的还原偶联已有大量的 报道, 但对映选择性合成的例子比较少, 仅仅在 2010 年 有一篇基于手性 $1,1^{\prime}$-联二䒬酚(BINOL)的单齿亚磷酰胺 配体诱导的镍催化的还原偶联合成轴手性联芳基二醛 的报道, 且只获得了中等程度的对映选择性 ${ }^{[4]}$. 另一方 面, 虽然 2-菜酚的不对称氧化偶联是合成简单 BINOLs 的有效方法, 但由 3-芳基取代的 2-菜酚的氧化偶联合成 3,3'-二芳基 BINOLs 优势骨架是极其困难和罕见的. 唯 一的例子是 Katsuki 课题组报道的 salen(Fe)不对称催化 2-萗酚的氧化偶联反应, 但是该反应的 $e e$ 值仅仅介于 $47 \% \sim 74 \%$ 之间 ${ }^{[5]}$. 因此, 发展由镍催化芳基卤化物的 还原偶联来合成高对映选择性、多取代的联芳烃化合物 的方法极其必要.

以电子作为反应试剂, 避免了化学氧化还原剂的使 用, 电化学合成作为一种原子经济、绿色环保的合成方 法目前正受到人们的关注和重视 ${ }^{[6]}$.

最近, 中国科学院上海有机化学研究所梅天胜课题 组以手性吡啶噁唑啉为配体, 镍为催化剂, 通过芳基溴 化物的电化学还原自偶联, 实现了联芳烃化合物的对映
选择性合成(Scheme 2).

(a) Formation of axially chiral Ar-Ar bonds via cross-cooupling reaction

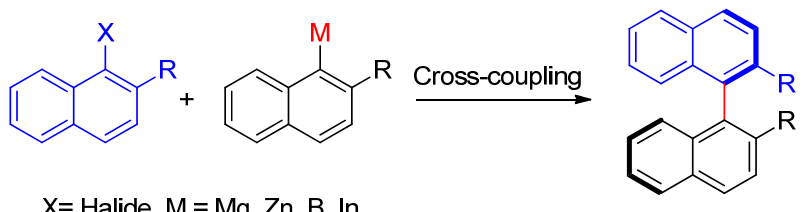

(b) Formation of axially chiral Ar-Ar bonds via oxidative coupling reaction

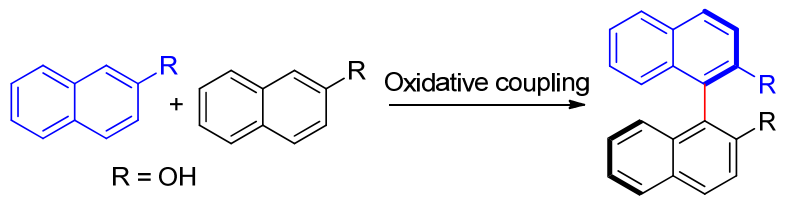

图式 1 联芳烃的对映选择性自偶联合成

Scheme 1 Enantioselective biaryl synthesis via homo-coupling

作者以 1-澳-2-甲氧基萗和 1-溴-2-芐氧基芸为模型 底物, 以 $\mathrm{NiCl}_{2} \cdot$ glyme 为催化剂首先进行了手性配体的 筛选, 发现当 1-澳-2-芐氧基萗为底物时, Ligand 13 可以 获得 93\% ee 的偶联产物. 在此基础上进一步确定了该 反应的最优条件, 当 $\mathrm{NiCl}_{2} \cdot$ glyme 和 Ligand 13 分别为 催化剂和配体, 铁为牺牲阳极, 泡沫镍为阴极, $\mathrm{NaI} / \mathrm{DMF}$ 为支持电解质体系, 单室电解槽, $15{ }^{\circ} \mathrm{C}$ 条件 下恒电流电解可以得到分离产率 $88 \%, e e$ 值为 $90 \%$ 的目 标产物.

该方法具有很好的官能团耐受性，芳环上取代基不 仅可以是烷基、醚、烯基、嗍、酯基和氯原子等，更为 重要的是, 3-芳基取代的溴代菜化合物同样也适用于该 方法. 作为对比，也进行了金属 $\mathrm{Mn}$ 为还原剂时相同条 件下的偶联反应. 结果表明, 电化学还原条件下可以获

* Corresponding author. E-mail: zengcc@bjut.edu.cn. Published online August 3, 2020. 
得更好的催化效率和更高的产率. 此外, 通过催化氢化 可以方便地得到无保护基的 BINOLs, 同时 ee 值保持不 变. 因此, 该电化学还原偶联方法提供了合成 BINOLs 和 3,3'-二芳基 BINOLs 化合物的有效策略.
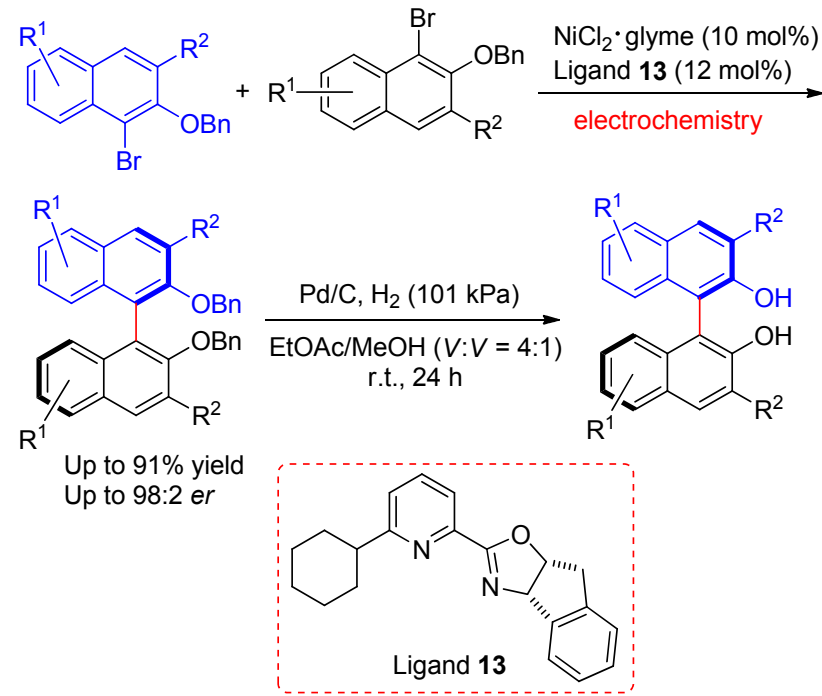

图式 2 联芳基化合物的不对称有机电化学合成

Scheme 2 Enantioselective biaryl synthesis via organometallic electrochemistry

该反应的机理被认为是: 催化剂 $\mathrm{Ni}$ (II)阴极还原形 成的 $\mathrm{Ni}(0)$ 先与甾代芳烃发生氧化加成形成芳基 $\mathrm{Ni}(\mathrm{II})$ 物种, 再在阴极还原为芳基 $\mathrm{Ni}(\mathrm{I})$. 此芳基 $\mathrm{Ni}(\mathrm{I})$ 物种与另 一分子卤代芳烃发生氧化加成和还原消除形成产物联 芳烃, 同时产生 $\mathrm{Ni}(\mathrm{I})$ 中间体. 最后该 $\mathrm{Ni}(\mathrm{I})$ 中间体在阴极 被还原为 $\mathrm{Ni}(0)$, 从而完成催化循环.

该工作对有机电合成工作者来说具有重要的参考 价值. 虽然 Jennings 等 ${ }^{[7]}$ 在 1976 年首次报道了溴苯的电 化学还原偶联, 因电化学特有的优势, 自 2017 年以来, 亲电试剂间的电化学还原交叉偶联再次受到重视. Hansen, Sevov, Fan 和 Bio, Loren 以及 Mei 等课题组 ${ }^{[8]}$ 先后报 道了镍催化电化学还原偶联形成新的 $\mathrm{C}-\mathrm{C}$ 键的工作,
但均不涉及对映选择性电化学反应. 最近 Reisman 等 ${ }^{[9]}$ 实现了第一例烯基卤和苄基卤间的不对称电化学还原 交叉偶联反应.

总之, 梅天胜课题组创造性地采用具有不对称结构 的手性吡啶啞唑啉配体，首次实现了镍催化的芳基卤化 物的对映选择性还原偶联反应，高产率和高对映选择性 地制备了轴手性的 BINOL 衍生物. 该反应在单室电解 池中, $15{ }^{\circ} \mathrm{C}$ 条件下进行, 操作简单, 为 BINOL 衍生物的 对映选择性合成提供了高效、经济的途径，为金属催化 的电化学对映选择性合成提供了理论和实践基础.

\section{References}

[1] Cherney, A. H.; Kadunce, N. T.; Reisman, S. E. Chem. Rev. 2015, $115,9587$.

[2] Tian, J.-M.; Wang, A.-F.; Yang, J.-S.; Zhao, X.-J.; Tu, Y.-Q.; Zhang, S.-Y.; Chen, Z.-M. Angew. Chem., Int. Ed. 2019, 58, 11023.

[3] Zhang, S.; Liao, G.; Shi, B. Chin. J. Org. Chem. 2019, 39, 1522 (in Chinese). (张硕, 廖港, 史炳锋, 有机化学, 2019, 39, 1522.)

[4] Chen, W.-W.; Zhao, Q.; Xu, M.-H.; Lin, G.-Q. Org. Lett. 2010, 12, 1072 .

[5] Egami, H.; Katsuki, T. J. Am. Chem. Soc. 2009, 131, 6082.

[6] (a) Hammerich, O.; Speiser, B. Organic Electrochemistry: Revised and Expanded, 5th ed., CRC Press, Boca Raton, FL, USA, 2015.

(b) Yan, M.; Kawamata, Y.; Baran, P. S. Chem. Rev. 2017, 117, 13230 .

[7] Jennings, P. W.; Pillsbury, D. G.; Hall, J. L.; Brice, V. T. J. Org. Chem. 1976, 41, 719.

[8] (a) Perkins, R. J.; Pedro, D. J.; Hansen, E. C. Org. Lett. 2017, 19 , 3755.

(b) Perkins, R. J.; Hughes, A. J.; Weix, D. J.; Hansen, E. C. Org. Process Res. Dev. 2019, 23, 1746.

(c) Truesdell, B. L.; Hamby, T. B.; Sevov, C. S. J. Am. Chem. Soc. 2020, 142,5884

(d) Li, H.; Breen, C. P.; Seo, H.; Jamison, T. F.; Fang, Y.; Bio, M. M. Org. Lett. 2018, 20, 1338 .

(e) Koyanagi, T.; Herath, A.; Chong, A.; Ratnikov, M.; Valiere, A.; Chang, J.; Molteni, V.; Loren, J. Org. Lett. 2019, 21, 816.

(f) Jiao, K.-J.; Liu, D.; Ma, H.-X.; Qiu, H.; Fang, P.; Mei, T.-S. Angew. Chem., Int. Ed. 2020, 59, 6520.

[9] DeLano, T. J.; Reisman, S. E. ACS Catal. 2019, 9, 6751.

(Li, L.) 